\title{
Evaluation of an active yeast propagation system on fermentation traits and quality of C.V. Carmenère wine
}

\author{
S. Manzano, S. Vargas, G. Casaubon, y Á. González \\ Center for Research and Innovation, Viña Concha y Toro, Chile
}

\begin{abstract}
Active dry yeasts (ADY, Saccharomyces cerevisiae) are widely used in oenology due to their potential benefits on the control of fermentation and quality reproducibility among other aspects. On the other hand, yeast propagation systems, so called Active Yeast Systems (AYS), can be useful to optimize the alcoholic fermentation (AF) initial lag phase and reduce production costs. The objective of this work was to determine the predominance of an ADY strain propagated by AYS and the impact of this inoculum on cv. Carmenère wine quality. Lalvin ICV D21 ADY strain was inoculate according to the protocol recommended by the manufacturer (T0), and in parallel, it was propagate by the AYS and then used as inoculum (T1). Yeast strain predominance analyzed by restriction fragment length polymorphism (RFLP) technique indicates that nine (out of 9) yeast colonies obtained from a single sample of the ADY, show the same electrophoretic pattern when compared to the ADY. The results show limited significant differences for the fermentation speed and the yeast cell counting. The result of the physicochemical analysis of the musts and resulting wines showed no significant differences between treatments. A triangular test showed no significant sensory differences between wines
\end{abstract}

\section{Introducción}

En la actualidad, las levaduras tienen función en diversos procesos tecnológicos e industriales. En las fermentaciones vínicas interviene un gran número de especies de levaduras a lo largo de todo el proceso, sin embargo, son las del género Saccharomyces y en particular Saccharomyces cerevisiae, las que lo llevan a término [1].

Las levaduras secas activas (LSA; Saccharomyces cerevisiae) son ampliamente utilizadas en enología por sus potenciales beneficios sobre el control de la fermentación y la reproducibilidad de la calidad, entre otros aspectos [2]. Sin embargo, estas representan un costo importante para bodegas industriales de gran tamaño con consumos superiores a $500 \mathrm{~kg}$ de levadura para una producción de $33.000 \mathrm{hL}$. Los sistemas de propagación de levaduras, llamados Sistemas de Fermento Activo (SFA), pueden ser útiles para optimizar la fase de latencia inicial de la fermentación alcohólica (FA) y reducir costos de producción. Se propone la preparación de pie de cuba de propagación a alta concentración celular que permite optimizar la fase de siembra. Estos preparados, con más de 200 millones de células/ml, aseguran una siembra de levaduras en plena actividad en 15 horas [3]. Por otra parte, este proceso representa un interés económico importante para la bodega, ya que permite reducir la cantidad de LSA usada [3]. El objetivo de este trabajo fue determinar la predominancia de una cepa de LSA propagada por SFA y el impacto de este inóculo sobre los parámetros de la fermentación y la calidad final del vino cv. Carmenère.

\section{Materiales y métodos}

\subsection{Uva}

Se utilizaron $6.000 \mathrm{~kg}$ de uva del cv. Carmenère, cosechada en el fundo Lourdes propiedad de Viña Concha y Toro S.A que se encuentra ubicada en la comuna de Pencahue, Chile $\left(35^{\circ} 26.78^{\prime} \mathrm{S}, 71^{\circ} 48.66^{\prime} \mathrm{O}\right)$. La cosecha se realizó a fines de abril, siendo definida mediante análisis de madurez industrial, realizado en forma manual y en bins de $450 \mathrm{~kg}$. Las unidades experimentales fueron randomizadas en la bodega previo a su molienda.

\subsection{Cepa de levadura}

La levadura utilizada para los procesos de SFA y fermentaciones alcohólicas fue Saccharomyces cerevisiae cepa Lalvin ICV D21 [6].

\subsection{Diseño experimental}

Se optó por un diseño experimental completamente al azar con tres repeticiones. Los tratamientos fueron los siguientes: T0: inoculación directa de LSA y T1: inoculación de fermento activo, obtenido desde la propagación de la LSA por un SFA.

\subsection{Fermento}

En el caso de la LSA, se realizó una inoculación siguiendo las recomendaciones del proveedor $20 \mathrm{~g} / \mathrm{hL}$ [6], en donde para T1, el método SFA consistió en propagar a partir de una dosis de $50 \mathrm{~g} / \mathrm{hL}$ de LSA usando una mezcla al 
Tabla 1. Análisis del mosto antes de la corrección de acidez.

\begin{tabular}{|c|c|c|c|c|c|c|c|}
\hline Tratamiento & $\begin{array}{c}\text { SST } \\
\%\end{array}$ & $\begin{array}{c}\text { AC total } \\
\mathrm{g} / \mathrm{L} \\
\text { sulfurica }\end{array}$ & $\begin{array}{c}\text { Sulfuroso } \\
\text { libre } \\
\text { mg/L }\end{array}$ & $\begin{array}{c}\text { Sulfuroso } \\
\text { total } \\
\mathrm{mg} / \mathrm{L}\end{array}$ & $\mathbf{P h}$ & $\begin{array}{c}\text { Acido } \\
\text { málico } \\
\text { g/L }\end{array}$ & $\begin{array}{l}\text { YAN } \\
\mathrm{mg} / \mathrm{l}\end{array}$ \\
\hline T0 & 26.6 & 2.40 & 16 & 35 & 3.90 & 1.1887 & 167 \\
\hline \multirow[t]{2}{*}{ T1 } & 26.6 & 2.23 & 25 & 46 & 3.93 & 1.2540 & 160 \\
\hline & ns & ns & ns & ns & ns & ns & ns \\
\hline
\end{tabular}

Tabla 2. Análisis de vino después del descube.

\begin{tabular}{|c|c|c|c|c|c|c|c|c|}
\hline Tratamiento & Alcohol \% & $\begin{array}{c}\text { Acidez } \\
\text { total g/L } \\
\text { sulfürica }\end{array}$ & $\begin{array}{c}\text { Acidez } \\
\text { volatil g/L } \\
\text { acacético }\end{array}$ & $\begin{array}{c}\text { Sulfuroso } \\
\text { libre } \\
\text { mg/L }\end{array}$ & $\begin{array}{c}\text { Sulfuroso } \\
\text { total } \\
\text { mg/L }\end{array}$ & pH & $\begin{array}{c}\text { Materia } \\
\text { reductora } \\
\text { g/L }\end{array}$ & $\begin{array}{c}\text { Intensidad } \\
\text { colorante } \\
\mathbf{4 2 0 , 5 2 0 , 6 2 0}\end{array}$ \\
\hline T0 & 14.4 & 4.8 & 0.33 & 18.4 & 29.7 & 3.42 & 1.30 & 25 \\
\hline T1 & 14.5 & 4.73 & 0.34 & 19.2 & 30.1 & 3.44 & 1.13 & 25 \\
\hline & $\mathbf{n s}$ & $\mathbf{n s}$ & $\mathbf{n s}$ & $\mathbf{n s}$ & $\mathbf{n s}$ & $\mathbf{n s}$ & $\mathbf{n s}$ & $\mathbf{n s}$ \\
\hline
\end{tabular}

$50 \%$ de agua y mosto centrifugado, sulfitado, para obtener un pie de cuba de 2000 lts de alta concentración celular, siguiendo protocolo del proveedor del sistema, realizando una aplicación del 1\%/L equivalente a $1 \mathrm{~g} / \mathrm{hL}$.

\subsection{Vinificación}

La uva fue despalillada, se aplicó sulfuroso $5 \mathrm{~g} / \mathrm{hL}$, se le realizaron análisis de sólidos solubles totales, acidez total, sulfuroso libre y total, $\mathrm{pH}$ y nitrógeno fácilmente asimilable por las levaduras por método enzimático. Se realizaron correcciones a $\mathrm{pH} 3.45$ y de amonio según el ${ }^{\circ} \mathrm{Bx}, 1 \mathrm{mg}$ de fosfato diamónico por gramo de azúcar. La vinificación se realizó en bins isotérmicos de 1000 L según protocolo estandarizado, se controló densidad y la temperatura se mantuvo entre 26 y $28^{\circ} \mathrm{C}$. Se realizó un pisoneo de 5 minutos cada 12 horas. Terminada la fermentación alcohólica, se descubó y se le realizó fermentación maloláctica (FML) sembrando con bacteria comercial $6 \mathrm{~g} / \mathrm{h}$. Finalizada la FML se procedió a sulfitar los vinos con $5 \mathrm{~g} / \mathrm{hL}$ de $\mathrm{SO}_{2}$. Luego, los vinos fueron trasegados, filtrados y envasados.

\subsection{Análisis microbiológico}

Durante la fermentación alcohólica, se efectuó un seguimiento de la población de levaduras a través del recuento celular por el método de la cámara de Thomas.

\subsection{Análisis molecular}

Al fermento activo T1 SFA se le realizó un análisis de predominancia con la técnica de fragmentos de restricción de longitud polimórfica (RFLP) del DNA mitocondrial, utilizada para determinar la predominancia de cepas de S. cerevisiae [4].

\subsection{Análisis químicos}

A los vinos se les realizaron análisis químicos de alcohol por destilación y aerometría, acidez total por determinación, alcalimetría con indicador, acidez volátil, método Blarez, sulfuroso libre y total, método de Ripper, $\mathrm{pH}$ por potenciometría, materias reductoras mediante el método Luff, intensidad colorante (IC) obtenida desde la lectura de DO 420, 520, $620 \mathrm{~nm}$, y ácido málico a través de un método enzimático [5].

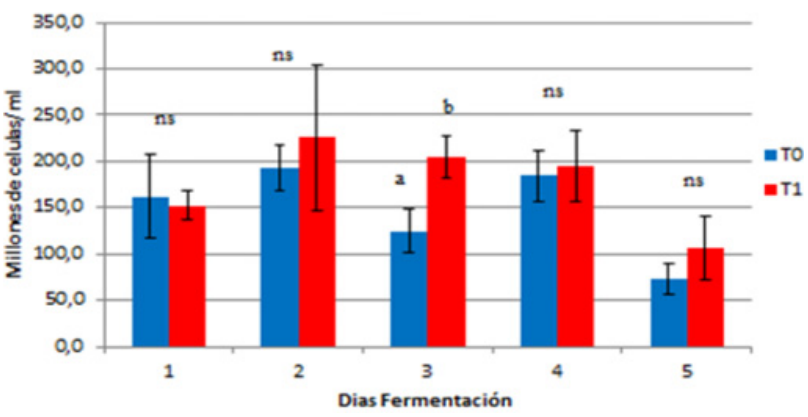

Figura 1. Grafico recuento viabilidad de levaduras por días de fermentación (millones de células/ml).

\subsection{Análisis estadístico y sensorial y estadístico}

El análisis de los datos, mosto, vino, recuento de viabilidad, velocidad de fermentación y cinética de fermentación, se llevó a cabo mediante un ANDEVA de una vía y comparaciones múltiples de medias por el método de Tukey.

El análisis sensorial se realizó a través de un test triangular usando pruebas no paramétricas [7].

\section{Resultados y discusión}

El análisis del mosto antes de la aplicación de los tratamientos no muestra diferencias significativas (ns) para ninguno de los compuestos y atributos analizados (Tabla 1).

Al observar los resultados analíticos obtenidos en el vino después del descube, se observan resultados sin diferencia significativa para los tratamientos T0 y T1, por lo cual, los sistemas de propagación por LSA y SFA no generarían cambios en el perfil analizado (Tabla 2).

El comportamiento del crecimiento de la población de levaduras cada 24 horas no fue significativamente diferente para T1 y T0 para los días 1, 2, 4 y 5, sólo en el día 3 existe una diferencia significativa en el nivel de población, terminando la fermentación el día 5 sin diferencias significativas, pero con una mayor población del tratamiento T1 SFA [8] (Fig. 1).

Al observar la velocidad de fermentación sólo se registran diferencias significativas en el segundo día de fermentación, donde T0 muestra una velocidad de 


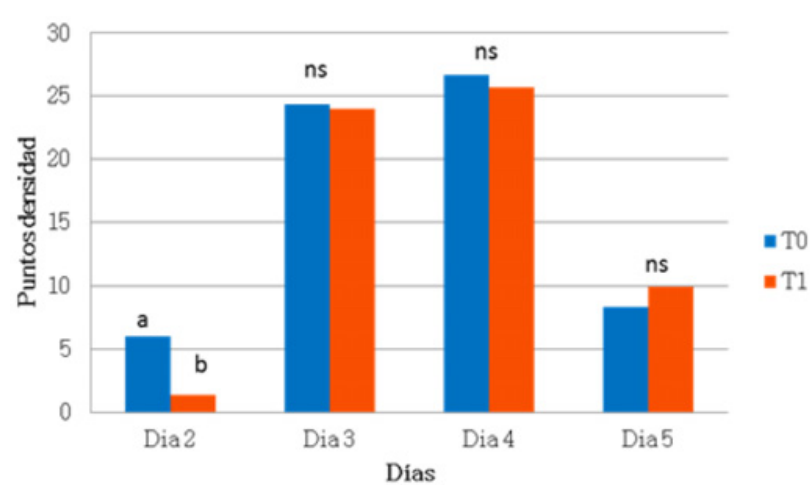

Figura 2. Gráfico velocidad de fermentación por día / bajada de puntos de densidad.

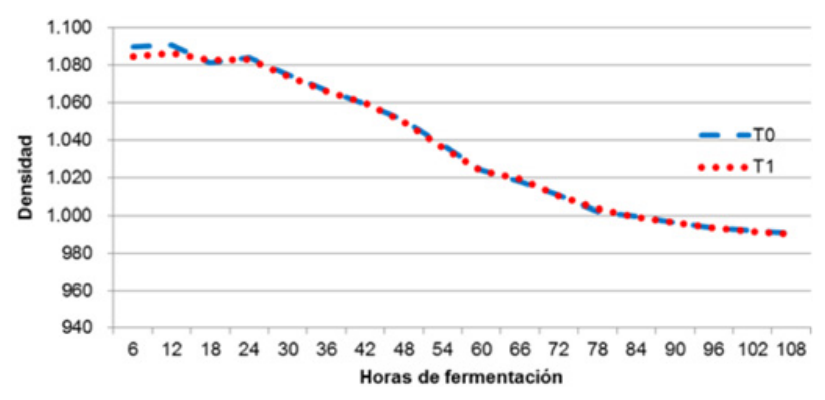

Figura 3. Cinética de fermentación: evolución de la densidad en fermentación en el tiempo para los tratamientos T0 y T1.

fermentación asociada a densidad que es mayor (Fig. 2). Esto podemos atribuirlo al mayor número de levaduras sembradas en el inóculo LSA con un recuento de viabilidad de 1.464 millones/ml de células y SFA 356 millones/ml de células.

El comportamiento de la FA en su cinética de fermentación manteniendo una temperatura constante de $26^{\circ} \mathrm{C}$ nos indica que no hay diferencias en la curva de densidad versus tiempo, comportándose de igual manera el tratamiento T0 y T1 [9] (Fig. 3).

El análisis molecular RFLP nos da como resultado que el SFA propagó un $100 \%$ la cepa Saccharomyces cerevisiae ICV D21, no existiendo ninguna colonia extraña al inóculo [4] (Fig. 4).

El análisis sensorial realizado a través de una prueba triangular con 13 jueces y 39 pruebas en total, mostró sólo 14 respuestas correctas. De éste resultado se puede concluir que los vinos no son significativamente distintos $(p=0.05)$ [7].

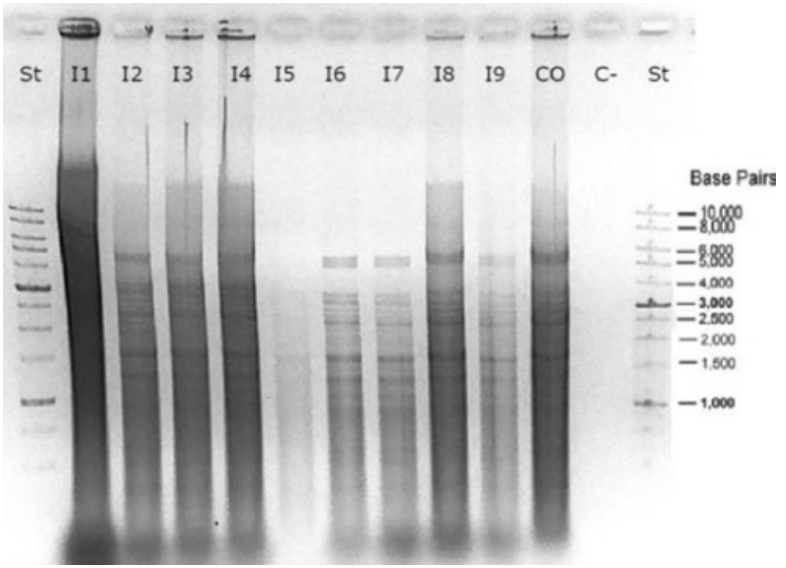

Figura 4. Análisis del patrón RFLP del DNA mitocondrial. 1A) Carriles I1-I9 = colonias aisladas de muestra fermentada, $\mathrm{CO}=$ cepa original, $\mathrm{C}-=$ control negativo, $\mathrm{ST}=$ estándar de tamaño molecular, 1B) digestión de la muestra I1.

\section{Conclusión}

Se puede concluir que el SFA utilizado propaga efectivamente la cepa de LSA, ya que no se encontraron evidencias de contaminación con otro patrón RFLP. Por otro lado, este sistema no tiene impacto sobre la calidad del vino C.V. Carmenère.

\section{Referencias}

[1] T. Török, R. Mortimer, K. Romano, P. Suzzi y, M. Polsinelli, J. Ind. Microbiol. 17, 303 (1996)

[2] I. Kamio, La Revolución de las Levaduras (I), (2012)

[3] http://www.oenoblog.info/2012/09/ fermentaciónrima- con-revolucion-1

[4] Querol, Molecular Monitoring of Wine Fermentations Conducted by Active Dry Yeast Strains, Appl. Environ. Microbiol. 58, 2948 (1992)

[5] E. Bordeau, J Scarpa, Análisis químico del vino (1998)

[6] http://catalogapp.lallemandwine.com/ uploads/yeasts/docs/02879b234a11d8 52887b817ebd075aba9b798641.pdf

[7] R.S. Jackson, Análisis sensorial de vinos (2009)

[8] P. Ribereau, D. Dubourdiu, B. Donéche, A. Lonvaud. Tratado de Enología, Microbiología del Vino (2003)

[9] C. Flanzy, Enología Fundamentos Científicos y Tecnológicos (2000) 